Medicina, Ribeirão Preto,

35: 367-370, jul./set. 2002

\title{
A CULTURA NA FMRP-USP
}

Maria Alice Nunes Coelho ${ }^{1} \&$ Anette Hoffmann ${ }^{2}$

${ }^{1}$ Assistente Administrativa Aposentada. ${ }^{2}$ Presidente da Comissão de Cultura e Extensão. Faculdade de Medicina de Ribeirão Preto - USP

\section{OS PRIMEIROS TEMPOS}

A FMRP-USP foi obra de um visionário, dotado de raro senso de determinação. Vingou, por ter Zeferino Vaz percebido o momento histórico, propício para sua implantação, e cativado pessoas que acreditaram em seu projeto de construir, no Nordeste Paulista, em terras ocupadas pela cultura cafeeira, então decadente, uma escola médica com propostas inovadoras. Zeferino correu mundo a vender seu sonho e atrair pessoas dispostas a dedicar-se integralmente ao ensino e à pesquisa. Não raro, os primeiros docentes e aqueles que os sucederam foram pessoas dotadas de razoável ou mesmo notável cultura. Coincidência ou propósito, o certo é que o projeto de Zeferino contou com a adesão de pessoas culturalmente diferenciadas que, em alguns casos, abandonaram carreiras já construídas alhures ou possibilidades de empregos promissores, no caso dos mais jovens. Talvez fosse mesmo um projeto, pois Zeferino escolheu, como seu braço direito, o poeta José Bento Faria Ferraz, que, por anos, fora secretário de Mário de Andrade, de quem herdara o gosto pela cultura e o espírito humanista. Em recente correspondência, José Bento descreve o espírito reinante na época da fundação da FMRP. "O início da Faculdade em abril de 1952, foi uma "Primavera de Praga", você não imagina. A cidade toda vibrava de um entusiasmo contagiante e era continuamente visitada pelos alunos secundaristas das cidades vizinhas interessadíssimos em conhecê-la. Cabia ao secretário (este seu criado) dar-lhes as boas vindas, por determinação expressa de Zeferino Vaz. Os jornais da cidade noticiavam as novas da Faculdade e logo passei a colaborar na imprensa local com meus artigos "soi disant" culturais (pobre de mim!)". Zeferino teve a clarividência de entender que sua obra deveria envolver toda a cidade e que cabia à Faculdade não só prestar assistência médica, mas também ser um núcleo de difusão cultural. Coube a José Bento um papel fundamental nesta última parte do projeto, o que se deduz de suas próprias palavras. "Logo no início da Faculdade surgiu a idéia de fundar uma Escola de Artes Plásticas onde fui convidado para colaborar como professor porque descobriram ter sido eu secretário de Mário de Andrade por vinte anos e também seu aluno no Conservatório Dramático Musical de São Paulo, onde fora professor. Ouvi dele aulas magistrais sobre Estética e História da Música."

Sob o risco de omissões, citaremos alguns professores daquele primeiro momento, que deixaram a marca de sua erudição em publicações que transcenderam o ambiente acadêmico. José Venâncio Pereira Leite, além de fisiologista na ampla acepção da palavra, foi, em sua juventude, exímio violinista, grande conhecedor da música erudita e articulista do Suplemento Cultural do jornal O Estado de São Paulo. Miguel Rolando Covian foi um pensador da cultura e de seu lugar na formação do universitário. Maurício Rocha e Silva enveredou pela história e a filosofia da ciência em seus livros "Lógica da Invenção" e "O Mito Cartesiano e Outros Ensaios”. A erudição de alguns não ficou registrada em textos, mas na memória de quem com eles conviveu. Lucien Lison estudava tratados antigos de medicina, escritos em latim. Fritz Koberle recitava "Os Lusíadas". Na geração seguinte, vamos encontrar nomes que conquistaram notoriedade nacional na área da literatura. Isaías Pessotti foi agraciado com o prêmio Jabuti em 1994, com seu livro "Aqueles Malditos Cães de Arquelau”. 
Nessa mesma época, a obra foi considerada o "Livro do Ano" pela Câmara Brasileira do Livro. João Garcia Leme, discípulo de Rocha e Silva, escreveu peças de teatro. Gyorgy Bohm publicou um alentado livro sobre as viagens de Enrico Caruso na América do Sul.

Na década de 1960, a convite de Zeferino Vaz e com anuência do Professor Lucien Lison, o artista italiano, Bassano Vaccarini, então radicado em Ribeirão Preto, executou um magnífico mural numa das paredes da sala de aulas práticas de Anatomia do Prédio Central da Faculdade, a respeito do qual escreveu a Profa. Maria Cecília França Lourenço, professora da FAU e Diretora da Comissão de Patrimônio Cultural da USP (CPC): "Quando foi realizado (o mural) representava uma arte bastante inovadora e o fato de ser requisitado distingue essa unidade como comprometida com a renovação. $\mathrm{O}$ artista agrega uma série de objetos ao mural abstrato, promovendo um choque de linguagens, muito caro ao período, em que se honrava a inteligência do fruidor levando-o a pensar e interpretar, segundo sua própria sensibilidade". Informou-nos o engenheiro Maomé Cozac que Vaccarini executava, a pedido de docentes, desenhos científicos ou fabricava moldes de peças anatômicas, material que infelizmente não foi localizado. Ainda parcialmente preservados estão os desenhos em vidro que executou na capela do Campus.

\section{O GRUPO PRÓ-MÚSICA}

Na década de 1960, alguns professores da FMRP criaram o grupo Pró-Música, com o objetivo de ampliar o panorama cultural da Faculdade e atrair estudantes e o público externo para os concertos que aconteciam na capela do Campus. O impulso inicial para a criação do grupo veio do então secretário da Faculdade, Márcio Massari, ele próprio pianista, com amplo relacionamento no ambiente musical de São Paulo. O primeiro presidente foi Miguel Rolando Covian. Trabalharam ao seu lado outros docentes, como José Venâncio Pereira Leite, André Cruz, Renato Migliorini e Humberto Menezes. Também ocupou a presidência, em anos subseqüentes, a Sra. Lurdes Gandra, professora de música e, atualmente, Presidente de Honra do Grupo.

\section{A ASSESSORIA CULTURAL}

No período de 1979 a 1983, na gestão do então Diretor da Faculdade de Medicina de Ribeirão Preto, Prof. Dr. José Eduardo Dutra de Oliveira, que acu- mulava o cargo e funções com a de Coordenador do Campus, foi criada a Assessoria Cultural, visando oferecer a seus alunos, funcionários e docentes, a possibilidade de participarem, num Campus formador basicamente de orientação na área da saúde, de atividades em outras áreas como Ciências Humanas. Foram desenvolvidas atividades de arte, literatura, pintura, música e, ainda, exposições de artes plásticas, instalando, no espaço físico do Banespa, recém-inaugurado (1981), uma Galeria de Arte. Essas atividades culturais desenvolveram-se ativamente naquele período, diminuindo com o decorrer de outras gestões, o número de propostas oferecidas. Vale ressaltar que a Coordenadoria do Campus, por volta de 1985, tornouse administração independente da direção executiva da FMRP.

Na gestão do Prof. Dr. Dalmo de Souza Amorim, correspondente ao quatriênio 1989-1992, foram adotadas ações e programas culturais, não convencionais a uma Escola Médica. Realizaram-se, no período, exposições artísticas (que, à época, estavam desativadas pela Assessoria Cultural do Campus), seminários em áreas não técnicas do conhecimento, palestras, concertos, cursos de verão, maratona de matemática (que se mantém até a presente data, tendo-se aprimorado e oferecendo incontestáveis benefícios a alunos de $2^{\circ}$ grau), publicações especiais voltadas à Memória Histórica da FMRP, como "Monte Alegre: Dos Tempos do Café à FMRP", "Memória dos Departamentos da FMRP” (Revista Medicina, vol. 25, n 1, 1992), "Opúsculo da FMRP", "Catálogo de Teses da FMRP", etc. Além dessas atividades foram também desenvolvidas ações diversas como vídeo-clube e entrevistas na TV (Jornal da Record). Em comemoração aos 40 anos da nossa instituição foi realizado o Baile Branco (retorno ao que um dia foi tradicional na sociedade ribeirãopretana), o lançamento do "folder" da FMRP e do carimbo e selo comemorativos pela Empresa Brasileira de Correios e Telégrafos.

De 1993 a 1997, sob a administração do Diretor Prof. Dr. José Antunes Rodrigues, continuou promovendo ações culturais como, Exposições/Mostras de Arte, Concertos, Seminários/Palestras Culturais, sob a responsabilidade de uma assessoria acumulada com as funções de Assessoria Administrativa.

Em 1998, a Assessoria Cultural promoveu o Curso de Extensão Universitária "Arte e Corpo", coordenado pela Profa. Elza Ajzenberg, da ECA-USP, e foi igualmente reconhecido como parte da disciplina de pós-graduação "A Medicina e os outros Saberes" e apoiado pelo então presidente da CPG, Milton César 
Foss. As palestras do curso foram reunidas numa publicação editada pelo Centro Mario Schemberg de Documentação da Pesquisa em Artes (ECA-USP) e apoiada pela FMRP, gestão Michel Pierre Lison. Nos anos subseqüentes, essa disciplina de pós-graduação vinculou-se à disciplina da FFCLRP-USP, denominada "Seminários em História e Filosofia das Ciências", já que ambas tinham por objetivo ampliar o horizonte cultural do estudante e abrir espaço para o público externo. Foram oferecidos os cursos "Rumo ao Ano 2000: Percorrer as Distâncias"(abril de 1999), "As viagens e a Ciência"(agosto de1999), "A Essência da Universidade"(outubro de 2000) e "O Tempo, Esse Grande Escultor" (setembro de 2001). As palestras desses cursos foram ministradas por estudiosos de diferentes áreas do saber e assistidas por pós-graduandos das diversas unidades do Campus e por pessoas da comunidade local e mesmo de cidades vizinhas.

O uso do saguão do prédio central da FMRP como espaço expositivo teve início na gestão do Prof. Dalmo de Souza Amorim e persiste até o presente. Permite aos passantes, nem sempre freqüentadores de museus e galerias, um contacto com a arte contemporânea. Gradativamente, firmou-se o compromisso de privilegiar exposições de artistas reconhecidos no cenário nacional, em conseqüência do que o espaço passou a ser reconhecido como um dos poucos locais da cidade de Ribeirão Preto a zelar por um padrão de qualidade, o que permitiu atrair exposições de artistas de renome internacional. Foi ali, em abril de 1998, que Tomie Ohtake fez o lançamento de uma série de gravuras, que depois foram apresentadas em galerias de várias capitais. Em 1997, foram exibidos desenhos de Marcelo Grassmann da série "A Donzela e a Morte", pertencentes ao colecionador Alexandre Biagi e que estiveram anteriormente em exposição no MASP, em São Paulo. Abrigou, em 1998,gravuras de Rubens Gerchman, o representante máximo da arte pop no Brasil, numa exposição realizada em parceria com o Museu de Arte de Ribeirão Preto (MARP) e inaugurada com uma palestra do próprio artista.

\section{O MUSEU DA FMRP-USP}

Em 1985, o Diretor da FMRP, Prof. José Augusto Laus Filho, designou, através de portaria, uma comissão, composta pelos Profs. Ruy Escorel Ferreira Santos, Miguel Rolando Covian e Albert Amin Sader e pelo acadêmico Osvaldo Cardoso de Santana Filho, para organizar o Acervo Histórico e planejar a insta- lação de um Museu Institucional. Ao grupo juntou-se, posteriormente, o Prof. Salim Moyses Jorge. A idéia do museu não vingou e, em ofício datado de 18 de março de 1986 e dirigido ao Diretor Laus Filho, o Prof. Ruy expressa sua preocupação com relação à guarda do material em poder da comissão, alertando para a necessidade de uma área física adequada. Na gestão do Prof. José Antunes Rodrigues (1993-1997), a sede do Centro Acadêmico "Rocha Lima", que ocupava área física próxima ao Prédio Central e ao Laboratório Multidisciplinar, foi transferida para nova construção, denominada "Centro de Vivência". Com a desocupação do pequeno espaço pelos estudantes, foram ali alocados fotos e documentos diversos que estavam sob a guarda da Assessoria Cultural, equipamentos construídos na Oficina Mecânica de Precisão e que serviram para ações técnicas de ensino e pesquisa nos diversos departamentos, formando, assim, a semente do Museu Histórico Institucional. Essa construção remonta aos primeiros anos da Faculdade, quando abrigou a casa de força, que distribuía energia elétrica para os prédios do Campus. Podemos ver sua robusta torre, em estilo arquitetônico similar ao do prédio central, em fotos aéreas datadas de 1952. A cessão dessa área física para abrigar o museu foi aprovada em reunião do Conselho Técnico-Administrativo da FMRP, em 13 de dezembro de 1996.

\section{A COMISSÃO DE CULTURA E EXTENSÃO}

A FMRP criou sua Comissão de Cultura e Extensão pró-tempore, em 13 de abril de 1999. Para compô-la, o Diretor Michel Pierre Lison designou os professores Edna Marturano, Marcos Felipe Silva de Sá, Rubens Ricco, Bernardo Mantovani, Anette Hoffmann e a acadêmica Patrícia Gonçalves Guimarães, presidente do Centro Acadêmico Rocha Lima. Como Secretário Geral, foi designado o Sr. Rogério Aparecido Mazzucato e, como Secretária de Atividades Culturais, a Sra. Maristela Medeiros Santos Silva. A designação definitiva da Comissão ocorreu em sessão ordinária da Congregação, no dia 13 de agosto de 1999, e a Sra. Maristela Medeiros Santos Silva passou a atuar como secretária, função que ocupa até a presente data.

\section{CONCLUSÃO}

Vimos que, nos primeiros tempos, a preocupação com a cultura brotou junto com a Faculdade de 
Medicina, como uma necessidade natural. Havia uma clara percepção de sua importância na formação humanística do médico. E uma visão da Medicina enquanto um humanismo. Com o correr dos anos, perdeu-se a informalidade e, talvez, aquela visão da Medicina, e as atividades culturais passaram a ser assumidas como programas oficiais, com concessão inclusive de créditos, no caso dos cursos. Não deixa de ser preocupante essa formalização, pois corremos o risco de propiciar uma cultura apenas funcional, mera fornecedora de créditos e certificados. Por isso, a questão cultural precisa ser continuamente repensada e entendida, não como algo que acrescente um verniz na formação do estudante, mas como uma questão de essência, já que interfere na construção de valores e nas concepções de mundo.

\section{BIBLIOGRAFIA CONSULTADA}

1 - DUTRA DE OLIVEIRA JE. Perfil de uma administração 1979-1983. Relatório da Diretoria. Ribeirão Preto, FMRP, 1983.

2 - UNIVERSIDADE DE SÃO PAULO. PREFEITURAADMINISTRATIVA DO CAMPUS DE RIBEIRÃO PRETO. Relatório Cultura e Extensão - 1989-1992. Ribeirão Preto, 1992.

3 - UNIVERSIDADE DE SÃO PAULO. FACULDADE DE MEDICINA DE RIBEIRÃO PRETO. Relatório da Assessoria Cultural 1993-1996. Ribeirão Preto, 1996.

3 - UNIVERSIDADE DE SÃO PAULO. FACULDADE DE MEDICINA DE RIBEIRÃO PRETO Relatório de Gestão - 1993-1997. Ribeirão Preto, 1997. 